\title{
Practical Design of an Airship
}

\author{
Yuan Mao Huang* and S. W. Chang $\dagger$ \\ National Taiwan University, Taiwan 10617, Republic of China
}

\begin{abstract}
Airships have great potential for transportation, detection, tourism, and advertisement. This article presents the results of a practical design of an airship. A wood model of the air bag is tested in the wind tunnel and the coefficient of air resistance is determined. A waterproof cloth and the effect of the load on the adhesive tape used to connect the air bag, the gondola, and the tail part are tested. The resistant forces, the centroid of components, and the required power of the airship are determined. With the technical and weight consideration, the conceptual design of the airship has been developed. Thereafter, the prototype of the airship is fabricated.
\end{abstract}

\section{Introduction}

W $\mathrm{OO}$ and Murthy ${ }^{1}$ performed the geometric linear and nonlinear static analyses and determined the free vibration characteristics of airships. Grech and Weigel ${ }^{2}$ reported the survey of the crashed USS Macon airship. Onda and Morikawa ${ }^{3}$ studied the structural design concept of the model, the design data, and the attitude control principle. Louchev ${ }^{4}$ developed a steady-state model of the temperature regime of airships and hot air balloon shells. Baum and Louchev ${ }^{5}$ analyzed the influence of conductance on the temperature regimes of thermally thin shells and truss constructions. Nagabhushan and Pasha ${ }^{6}$ derived the equations of motion to investigate analytically the lateral and directional maneuverability characteristics and the powered yaw control augmentation of an advanced airship.

The purpose of this report is to present the results of a practical design of an airship. It is assumed that the windspeed is $10 \mathrm{~m} / \mathrm{s}$. It is desirable that helium provides the lift of the airship, that the airproof cloth has enough strength, that the airship is able to change the altitude and direction arbitrarily, that the airship be easily maintained and transported, that its weight is light, and that the factor of safety is high.

\section{Phases of Design}

The front-soft and rear-hard structure is determined during the conceptual design. The wood model of the airbag is used to determine the air resistance and the dynamics of the airship from the wind-tunnel test, and the result is used for the embodiment design. The dimensions and the strength of the airship are determined from the numerical calculation during the detailed design. The aft skeleton and the gondola are produced after the test of the cloth and connecting adhesive tape. The prototype of the airship is then fabricated within six months from the beginning of the work.

\section{Experimental Data}

In order to determine the air resistance during the flight of the airship, a wood model of the air bag with the scale of 1:30 is fabricated. The temperature and the density of the air are $14^{\circ} \mathrm{C}$ and $1.226 \mathrm{~kg} / \mathrm{m}^{3}$, respectively. The weight of the mounted bar is $400 \mathrm{~g}$. The measured strain of the mounted bar is 238 $\times 10^{-6}$. A piece of waterproof cloth with the dimensions of $10 \times 10 \mathrm{~cm}$ and the thickness of $0.0844 \mathrm{~mm}$ is used in the

Received May 9, 1994; revision received May 1, 1995; accepted for publication May 26, 1995. Copyright (C) 1995 by the American Institute of Aeronautics and Astronautics, Inc. All rights reserved.

*Professor, Department of Mechanical Engineering.

$\dagger$ Student, Department of Mechanical Engineering. test, and the temperature of the water against the cloth is $20^{\circ} \mathrm{C}$. No bubble exists when the water pressure is $1.125 \mathrm{~atm}$ and some small bubbles attach on the side of the cloth when the water pressure is $1.216 \mathrm{~atm}$. If the load acted on this piece of cloth is $40 \mathrm{~g}$, the elongation, stress, and strain are $1 \mathrm{~mm}$, $46,493 \mathrm{~N} / \mathrm{m}^{2}$, and 0.01 , respectively. Therefore, according to Hook's law, the modulus of elasticity is $47.4 \mathrm{~kg} / \mathrm{cm}^{2}$. The Kyosho Le Mans 360 Gold electric racing motor is used with the $7.2 \mathrm{~V}$ and $1200 \mathrm{~mA} \mathrm{Ni-Cd}$ batteries for the dynamic test. The results of the thrust force are shown in Table 1 . If the 8$\mathrm{V}$ and 6-A lead batteries are used, the thrust forces remain about 710 and $700 \mathrm{~g}$ during $0-60$ and $60-180 \mathrm{~s}$, respectively.

Since a strong adhesive tape was not available during fabrication, a common adhesive tape with $2 \times 2 \mathrm{~cm}$ was used to connect the air bag, the gondola, and the tail part. The results of the effect of normal load acted on it are shown in Table 2. The tensile strength of the adhesive tape is $0.185 \mathrm{~kg} /$ $\mathrm{cm}^{2}$. If it is used to sustain the transverse load, the results are shown in Table 3. The transverse strength of the material is $0.3 \mathrm{~kg} / \mathrm{cm}^{2}$.

The Reynolds number is defined as $R e=(\rho V L / \mu)$, where $\mu$ is the viscosity of air and $L$ is the characteristic length that is the maximum diameter of the air bag. ${ }^{7}$ Some calculated results are obtained based on the experimental data. For a small deformation, the strain is proportional to the load that can be used to determine the coefficient of air resistance defined as $C_{d}=\left(2 D / \rho V^{2} A\right)$, where $D$ is the resistance, $\rho$ is the density of air, $V$ is the speed of air, and $A$ is the projection area of the air bag. The coefficient of air resistance vs the Reynolds number is shown in Fig. 1.

\begin{tabular}{rr}
$\begin{array}{c}\text { Table 1 } \\
\text { of the electric motor }\end{array}$ & \begin{tabular}{r} 
Thrust force \\
\multicolumn{2}{c}{$\mathrm{s}$}
\end{tabular} \\
\hline 0 & 710 \\
20 & 710 \\
40 & 655 \\
60 & 660 \\
80 & 645 \\
100 & 545 \\
120 & 655 \\
140 & 650 \\
160 & 645 \\
180 & 605 \\
200 & 535 \\
220 & 420 \\
240 & 45 \\
260 & 30 \\
280 & 15 \\
300 & 6 \\
320 & $0-4$ \\
\hline \hline
\end{tabular}


Table 2 Effect of the normal load on the adhesive tape

\begin{tabular}{ll}
\hline \hline Load, $\mathrm{kg}$ & \multicolumn{1}{c}{ Effect } \\
\hline 0.4 & No \\
0.65 & No \\
0.8 & No \\
3.7 & Noise of crack \\
4.0 & Separation \\
7.1 & Separation \\
\hline \hline
\end{tabular}

Table 3 Effect of transverse load on the adhesive tape

\begin{tabular}{ll}
\hline \hline Load, $\mathrm{kg}$ & \multicolumn{1}{c}{ Effect } \\
\hline 0.4 & No \\
1.0 & No \\
1.2 & Separation \\
\hline
\end{tabular}

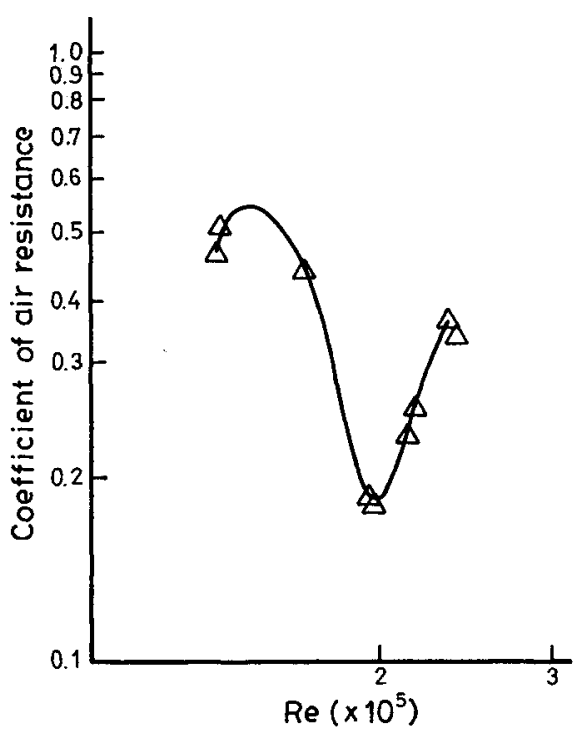

Fig. 1 Coefficient of air resistance vs the Reynolds number.

\section{Numerical Calculation}

Since the coefficient of air resistance drops and then increases, the flow is changed from the laminar flow to the turbulent flow. On the basis of the dynamic simulation, $R e$ model $=R e$ real, the speed of air blown to the wood model is 30 times that of wind blown to the real air bag. The maximum speed of air in the wind tunnel is $14.03 \mathrm{~m} / \mathrm{s}$. The Froude numbers of the wood model and the real air bag are the same for the dynamic simulation. It can be written as

$$
\left.\frac{D}{\rho v^{2} L^{2}}\right|_{\text {model }}=\left.\frac{D}{\rho v^{2} L^{2}}\right|_{\text {real }}
$$

The air resistance acted on the model is $0.10564 \mathrm{~N}$. If the maximum speed is $10 \mathrm{~m} / \mathrm{s}$ during the horizontal flight and $C_{d}$ remains 0.33137 for the reason of safety, the air resistance of the real air bag is $4.924 \mathrm{~kg}$. In other words, the air resistance is increased to $4.924 \mathrm{~kg}$ with the maximum flight speed. If the maximum value of $C_{d}$ of 0.49797 is used for the test, the air resistance becomes $7.399 \mathrm{~kg}$.

Two alike electric racing motors are installed on the air bag. From the dynamic test it is known that the maximum thrust force of each electric motor is $0.71 \mathrm{~kg}$. When the air resistance for the maximum speed is $4.924 \mathrm{~kg}$, the difference of the power required is $3.504 \mathrm{~kg}$. Therefore, a third power
Table 4 Weights and the centroids of all components

\begin{tabular}{lcl}
\hline \hline Item & Weight, $\mathrm{g}$ & Centroid $(x, y), \mathrm{m}$ \\
\hline Helium & 3064 & $(3.2238,0.0017)$ \\
Air bag & 3115 & $(3.1559,0)$ \\
Gondola & 4853 & $(1.8300,-0.957)$ \\
Tail wing & 1216 & $(60293,0)$ \\
Aft skeleton & 1273 & $(6.5046,0)$ \\
Rear wheel & 50 & $(6.125,-0.950)$ \\
Ring & 35 & $(0,0)$ \\
Adhesive tape & 360 & $(0.5925,0)$ \\
\hline \hline
\end{tabular}

source is required. The maximum power of the remote-control electric motor from the available data is $0.1 \mathrm{hp}$ that is equivalent to a two-stroke engine with the 0.1 -in. ${ }^{3}$ engine displacement. If the mechanism of the dynamic transmission is similar, the thrust force of the propeller is proportional to the engine power output. Hence, an engine with the 0.5 -hp output is used for safety.

From the wind-tunnel test, it is seen that the separation of air from the model occurs. The profile of the air bag is modified to reduce the resistance. Since the full motion wing control is used for the airship, the tail wing rotary shaft and the control mechanism occupy some space. The length of the air bag is determined to be $6.15 \mathrm{~m}$. The lift coefficient of helium is $1.018 \mathrm{~kg} / \mathrm{m}^{3}$ obtained from Woo and Murthy. ${ }^{1}$ The volume and the lift are calculated to be $11.004 \mathrm{~m}^{3}$ and $11.0202 \mathrm{~kg}$, respectively. The buoyancy center located in the $x-y$ coordinate is determined to be $(3.119,0) \mathrm{m}$. The weight of the air bag is determined to be $3115 \mathrm{~g}$. The pressure of helium is 1.1 atm in order to remain the shape of the air bag.

The purpose of the tail wing is to balance and control the direction of flight. In order to improve the maneuverability and reduce the air resistance of the air bag, the full motion type is designed and the NACA 63009 wing section is used. The tail wing is fabricated to be trapezium. The induced drag is increased, but fabrication is easy and the structure is strong. In order to keep the perpendicular tail wing in the range of the airflow to increase maneuverability, the wing end of the tail wing is slightly bigger than the maximum radius of the air bag. Each piece of the tail wing is the same so that it is easy to be repaired and exchanged. A honeycomb structure that is light, but strong, is used.

The aft skeleton is used to place the transmission equipment of the tail wing. It must be strong to sustain the force of strong wind. An independent air bag, that must also be light and strong, is located at the rear portion to increase the lift. The profile of the rear air bag is made of high-density polyester. The rotary portion is made with the structure of two perpendicular trusses. The rotary shaft passes through it. The servo and the bearing are supported by the structure. The important part is enforced by the plywood. The air bag of the tail end is behind the aft skeleton. The volume and lift are $0.349 \mathrm{~m}^{3}$ and $0.354 \mathrm{~kg}$, respectively. The weights and the centroids of the parts are shown in Table 4.

The total weight of $10.902 \mathrm{~kg}$ is smaller than the lift, 11.556 $\mathrm{kg}$. The centroid is located at $(3.2112,-0.4681) \mathrm{m}$. When it is under a no-load condition, the airship goes up slowly and the inclined angle is $1.54 \mathrm{deg}$.

If the airship is under a no-load condition and its speed is $10 \mathrm{~m} / \mathrm{s}$ in the horizontal direction, the calculated results of the lift, weight, resistance, and thrust force of the airship are $11.556,10.902,4.924$, and $4.924 \mathrm{~kg}$, respectively, and their centroids are located at $(3.2238,0.0017) \mathrm{m},(3.2112,-0.4681)$ $\mathrm{m},(0,0)$, and $(1.875,-0.978) \mathrm{m}$, respectively. Therefore, the force acted on the tail wing is $1.452 \mathrm{~kg}$. The coefficient of lift of the NACA 63009 is $0.111 / \mathrm{deg}$, and the inclined angle is determined to be $4.1 \mathrm{deg}$.

The area of the tail wing NACA 63009 is $0.51 \mathrm{~m}^{2}$, and the buoyancy center is located at $(6.4275,0) \mathrm{m}$. If the speed of the airship is $10 \mathrm{~m} / \mathrm{s}$ horizontally and the maximum operation 


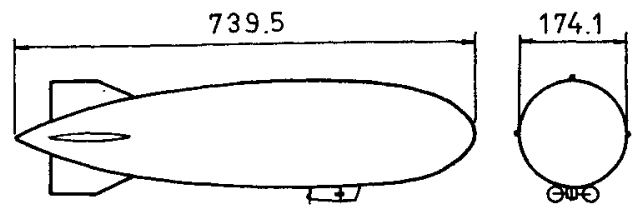

Fig. 2 Airship (in cm).
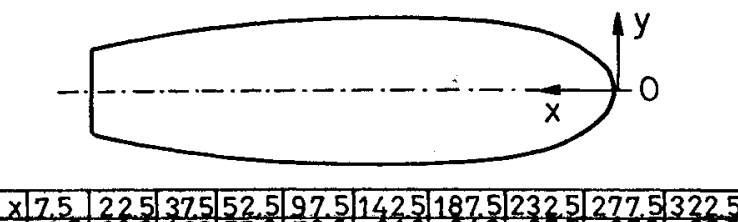
\begin{tabular}{l|l|l|l|l|l|l|l|l|l|l|l|}
\hline$y$ & 19.5 & 36.0 & 48.0 & 57.0 & 73.5 & 81.0 & 84.0 & 85.5 & 87.0 & 87.0 \\
\hline
\end{tabular}

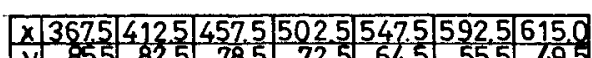

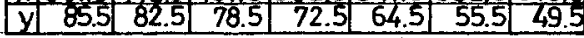

Fig. 3 Dimensions of the airship (in $\mathrm{cm}$ ).

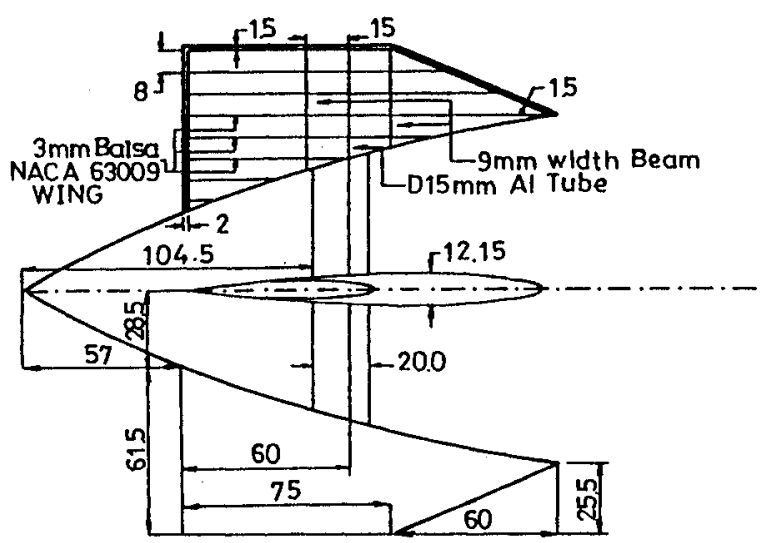

Fig. 4 Tail wing of the airship (in $\mathrm{cm}$ ).

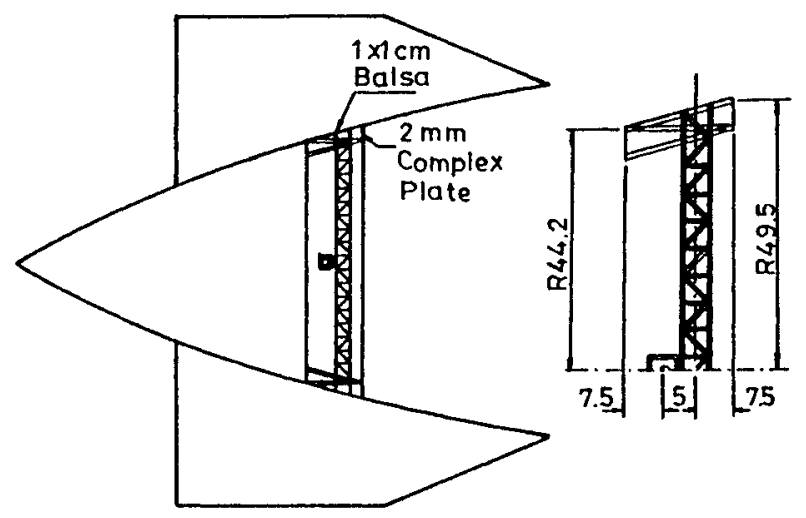

Fig. 5 Assembly support structure of the aft skeleton (in $\mathrm{cm}$ ).

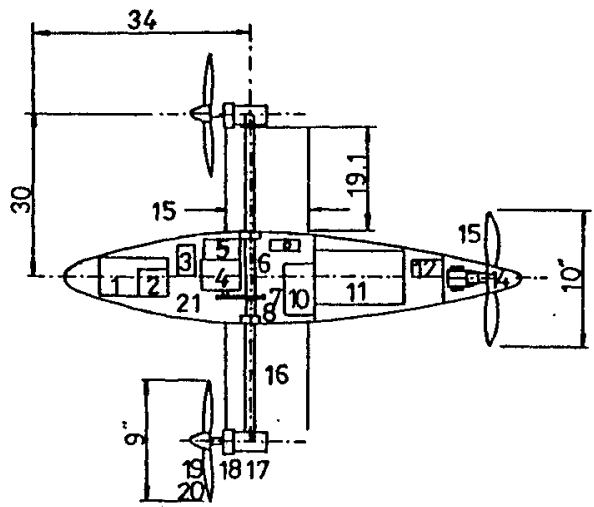

Fig. 6 Gondola (in cm).

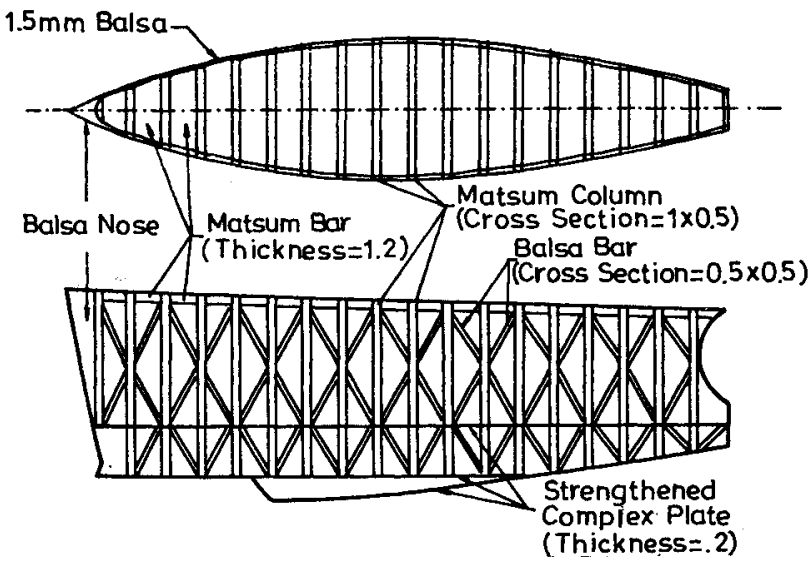

Fig. 7 Support structure of the gondola (in $\mathrm{cm}$ ).

angle of the tail wing is $\pm 10 \mathrm{deg}$, the moment is $22.7547 \mathrm{~kg}$ $\mathrm{m}$. The horizontal tail wing must assist the stability of the flight in the horizontal direction. If the electrical motor does not change the direction of flight, the moment is $13.4253 \mathrm{~kg}$ $\mathrm{m}$ for $+10 \mathrm{deg}$ and $32.0841 \mathrm{~kg}-\mathrm{m}$ for $-10 \mathrm{deg}$, respectively.

If the action of the tail wing is not considered, to rise and lower depends on the electrical motor. If the turning angle is less than $5 \mathrm{deg}$, the original direction of the thrust force does not change significantly. The moments of the electrical motor are 0.8465 and $0.4886 \mathrm{~kg}-\mathrm{m}$ for $+5 \mathrm{deg}$ and $-5 \mathrm{deg}$, respectively. If it is turned to the thrust line and the total centroid is on the straight line, the moment is zero and the turning angle is $-18.07 \mathrm{deg}$.

\section{Results}

The error of the measured data may be up to $\pm 3.5 \%$. The airship designed is shown in Fig. 2. The length and the maximum diameter are 739.5 and $174.1 \mathrm{~cm}$, respectively, as shown in Fig. 3. The tail wing is shown in Fig. 4. The assembly support structure of the aft skeleton is shown in Fig. 5. The gondola is shown in Fig. 6. The support structure of the gondola is shown in Fig. 7. The prototype of the airship has been in the sky twice for demonstration.

\section{Acknowledgments}

The authors would like to express their sincere thanks to the aviation club of the National Taiwan University, especially, G. G. Cheng, F. Y. Hsu, G. L. Huang, and G. Z. Chu for the assistance to design and fabricate the airship, and the National Science Council of the Republic of China for Grant NSC 82-0401-E-002-425 to complete this article.

\section{References}

${ }^{1}$ Woo, J.-H., and Murthy, V. R., "Static and Dynamic Analysis of Airships," Journal of Aircraft, Vol. 25, No. 9, 1988, pp. 790-795.

${ }^{2}$ Grech, C. V., and Weigel, A. M., "Discovery and Exploration of the USS Macon," Proceedings of Oceans '91, The Oceanic Engineering Society of IEEE, Piscataway, NJ, 1991, pp. 179-182.

3Onda, M., and Morikawa, Y., "Acrobatic Airship," SAE Transactions, Vol. 100, Sec. 1, Pt. 2, 911994, 1991, pp. 2101-2105.

${ }^{4}$ Louchev, O. A., "Steady State Model for the Thermal Regimes of Shells of Airships and Hot Air Balloons," International Journal of Heat and Mass Transfer, Vol. 35, No. 10, 1992, pp. 2683-2693.

'Baum, I. V., and Louchev, O. A., "Conductive Length in Heat Exchange Problems of Shells and Truss Constructions," International Journal of Heat and Mass Transfer, Vol. 35, No. 11, 1992, pp. 28152822 .

${ }^{6}$ Nagabhushar, B. L., and Pasha, R. P. K., "Analysis of Airship Lateral Maneuverability," Journal of Aircraft, Vol. 29, No. 3, 1992, pp. 299, 300.

${ }^{7}$ Fox, R. W., and McDonald, A. T., Introduction to Fluid Mechanics, 3rd ed., Wiley, New York, p. 304. 